\title{
Forniceal and hippocampal atrophy in temporal lobe epilepsy patients with a history of complex febrile convulsion
}

\author{
Kaan Yücel ${ }^{1}$ (D), Bahattin Hakyemez ${ }^{2}$ (D), İbrahim Bora ${ }^{3}$ (D) \\ ${ }^{1}$ Department of Anatomy, School of Medicine, Izmir Democracy University, Izmir, Turkey \\ ${ }^{2}$ Department of Radiology, School of Medicine, Bursa Uludağ University, Bursa, Turkey \\ ${ }^{3}$ Department of Neurology, School of Medicine, Bursa Uhudă̆ University, Bursa, Turkey
}

\begin{abstract}
Objectives: Temporal lobe epilepsy (TLE) is the most common seizure type in adults. Recent studies showed that $28-58 \%$ of TLE patients had a previous history of complex febrile convulsions (CFC). We compared the hippocampal volumes and volumes of amygdaloid body and widths of fornix and mammillary bodies on magnetic resonance imaging (MRI) of TLE patients with and without history of CFC.

Methods: MRI scans of 42 subjects retrospectively examined. The amount of atrophy in hippocampus, amygdaloid body, fornix and mammillary bodies were determined by two formulas depending on the mean values of the controls.

Results: We found no difference between TLE patients with a history of CFC and TLE patients without such a history in terms of all the quantitative measurements results ( $p>0.05$ ) except the absolute right-left hippocampus volume and fornix \% difference rate $(p<0.01, p<0.05$ respectively).

Conclusion: Forniceal atrophy was more prominent in the TLE group of patients with previous CFC history when compared to those patients without a CFC history. The CFCs should not be underestimated in the childhood, as they are associated with more atrophy in the particular brain structures in patients with TLE.
\end{abstract}

Keywords: complex febrile convulsion; limbic system; magnetic resonance imaging; morphometry; temporal lobe epilepsy

Anatomy 2021;15(2):137-144 @2021 Turkish Society of Anatomy and Clinical Anatomy (TSACA)

\section{Introduction}

Epilepsy is an umbrella term characterized by epileptic seizures. An epileptic seizure results from the transient occurrence of several clinical symptoms due to abnormal discharge of the neurons in the brain. ${ }^{[1]}$ The lifetime prevalence of epilepsy has been reported as 7.60 per 1000 persons. ${ }^{[2]}$ Temporal lobe epilepsy (TLE) is the most common type of epilepsy in both adolescents and adults being $2 / 3$ of all the epileptic patients undergoing surgery. ${ }^{[2,3]}$ Previous studies revealed that $40 \%$ of TLE patients suffer from Ammon's horn sclerosis, hippocampal sclerosis or by its more appropriate name mesial temporal sclerosis (MTS) ${ }^{[4,5]}$ Volumetric changes are typical in TLE patients; moreover, reduction in hippocampal volume is one of the diagnostic criteria for MTS. ${ }^{[6]}$ Enlargement in amygdaloid body ${ }^{[7,8]}$ and decreases in the volumes of extratemporal structures such as thalamus ${ }^{[9]}$ are of most commonly reported findings in TLE patients.

The size of the fornix, which constitutes the major output pathway of the hippocampus has also been reported to decrease in TLE patients compared to the controls. ${ }^{[10,11]}$ In addition, the width of mammillary body on MRI was investigated to uncover its role in seizure lateralization by $\mathrm{Ng}$ et al. ${ }^{[1]}$

MRI serves as a useful tool that can be used in diagnosis of TLE and for evaluating the morphometric changes and understanding the etiopathogenesis of TLE. However, morphological changes in limbic system structures other than hippocampus and amygdaloid body were not evaluated sufficiently. ${ }^{[12]}$ 
In TLE one of the most important concepts the MRI morphometric studies focused at is its relation with complex febrile convulsion (CFC) of the childhood. ${ }^{[13]}$ Febrile convulsions are convulsions induced with fever caused by infections other than central nervous system infection. To differentiate febrile convusions from epilepsy, the patients should not have a history of any afebrile convulsion except neonatal convulsions which is seen between 1 month-5 years old in early childhood. ${ }^{[14,15]}$ They are seen in $2-4 \%$ of all the children. ${ }^{[16]} 2-10 \%$ of the children who suffer from febrile seizures later have one or more unprovoked seizures. ${ }^{[16]} 75 \%$ of these febrile seizures are actually complex febrile convulsions in nature. ${ }^{[5]} \mathrm{A}$ CFC is characterized by one or more of the following aspects : (a) the onset should be a partial onset, (b) it must have a duration of more than 10-15 minutes, ${ }^{[16]}$ (c) multiple seizures should occur in 24 hours. ${ }^{[5]}$ Sometimes 30 minutes is used as a criterion for longer duration. ${ }^{[17]} 28-58 \%$ of TLE patients were reported to have history of CFC (TLE-CFC[+] patients). ${ }^{[17-19]}$ Especially long duration of $\mathrm{CFC}$ is an important predictor for determining risk for developing TLE. ${ }^{[20]}$ In an animal study it was shown that the number of febrile convulsion attacks were related to development of TLE. ${ }^{[2]}$ In the studies with the post-operative specimens the number of neurons in TLE-CFC $[+]$ patients tended to decrease more than the patients without a history of CFC (TLE-CFC[-] patients). ${ }^{[22,23]}$ Several theories had been proposed by different authors to explain the relation between CFCs of the childhood and TLE including TLE patients having a predisposition for $\mathrm{CFCs}^{[24]}$ and inflammatory mechanisms. ${ }^{[2]}$

Reduction in size of hippocampus in TLE-CFC[+] patients was reported to be more than the patients without such a history. ${ }^{[13,26-28]}$ However, some authors contradicts this result and reported no relation with hippocampal volume reduction and existence of history of CFC in TLE patients. ${ }^{[29]}$

It is evident that not every TLE patient with a hippocampal atrophy has a history of CFC. ${ }^{[30]}$ Hippocampal volume reduction after CFC detected by MRI was observed as a marker of acute damage. ${ }^{[3]]}$ The size of amygdaloid body seems to reduce more in TLE-CFC $[+]$ patients than the TLE-CFC[-] patients. But this change revealed to be relatively less when compared with reduction in hippocampal volume. ${ }^{[28]}$

Fornix is the primary efferent pathway of the hippocampal formation and the forniceal fibers mostly end in the mammillary bodies. Although TLE-CFC $[+]$ patients and TLE-CFC[-] patients were compared according to reduction in size of hippocampus and amygdaloid body, no comparison was made between the sizes of fornix and mammillary bodies. In this study, we aimed to asses the relation between hippocampus and amygdaloid body volumes, the width of fornix and mammillary bodies and the presence of history of CFC in TLE patients.

\section{Materials and Methods}

The study was conducted in 84 adults with equal number of patients and controls; the patient group included 42 cases (23 males, 19 females) having complex partial seizures originating from the temporal lobe. The patients had a mean age of $30.69 \pm 13.34$ and they were outpatients of the Neurology Clinic of Medical Faculty of Uludağ University. The patients with space-occupying lesions (tumor, scar etc.) were not included to the study. The patients were taking their anti-epileptics in the prescribed doses and free of any seizure during the study period. The control group included 42 healthy volunteers with a mean age of $31.09 \pm 12.06$. The controls were not taking any medication or hormones etc. One case in each group was left-handed and all the other cases in both groups were right handed. The history of CFC in childhood was questioned and recorded. CFC was defined as febrile seizures occurred before 5 years of age, lasting 20 minutes or longer without any underlying pathology of the central nervous system. The "age of epilepsy onset" was defined as the age when the first unprovoked afebrile seizure was seen. The "epilepsy duration" referred to the time interval between the first afebrile seizure and the time when MRI was performed.

MRI investigations were performed with 1.5 Tesla MRI scanner (Magnetom, Siemens, Erlangen, Germany). The measurement of intracranial area was performed at the midsagittal plane using sagittal $\mathrm{T} 1$ weighted Spin Echo (SE) sequences. The images of hippocampus and amygdaloid body were acquired at oblique coronal plane using a section thickness of $3 \mathrm{~mm}$ without any gap and using T1 turbo Inversion Recovery (IR) sequence.

The volume of hippocampus and amygdaloid body and the width of fornix and mammillary bodies were measured on 1.5 T MRI unit in both TLE and the control group. Assessing the images by the raw data without being normalized according to brain size one can get wrong results especially when bilateral atrophy exists. $^{[32-35]}$ Since the brain size can affect the volumes of hippocampus and amygdaloid body; we normalized the volume of hippocampus and amygdaloid body according to the following formula:

[Mean mid-intrasagittal area of the control group $x$ volume of hippocampus or amygdaloid body] / mid-sagittal area of the patient (Figure 1). ${ }^{[1]}$ 
We used Cavalieri's principle while performing volumetric measurements. ${ }^{[35,36]}$ Normalized hippocampus volume, the width of fornix and mammillary bodies were acquired after performing measurements using the images acquired from T1-weighted oblique coronal sections in 42 cases with TLE. One of the patients had artefacts in the scans; therefore, it is excluded. The hippocampus and amygdaloid body were drawn manually by a cursor in each section where they were seen, and the area measurement was calculated automatically. The sum of the areas were then multiplied by the section thickness $(0.3 \mathrm{~cm}){ }^{[11]}$ We then normalized the volumes accordingly.

Hippocampus was delineated on the coronal slices by the following borders; ${ }^{[12]}$ posterior border: crus of fornix; superior border: choroid plexus; inferior border: subiculum and parahippocampal gyrus; lateral border: temporal horn of the lateral ventricle; median border: cisterna ambiens (Figure 2). For the amygdaloid body, following borders on the coronal plane were used to asses its volume; ${ }^{[12]}$ posterior border: optic tract; superior border: a horizontal line drawn from the entorhinal sulcus; inferior and lateral borders: temporal horn and white matter of temporal lobe; medial border: ambient gyrus. The gyrus ambiens was seperated from gyrus parahippocampalis by the free margin of tentorium; uncal recess (Figure 3).

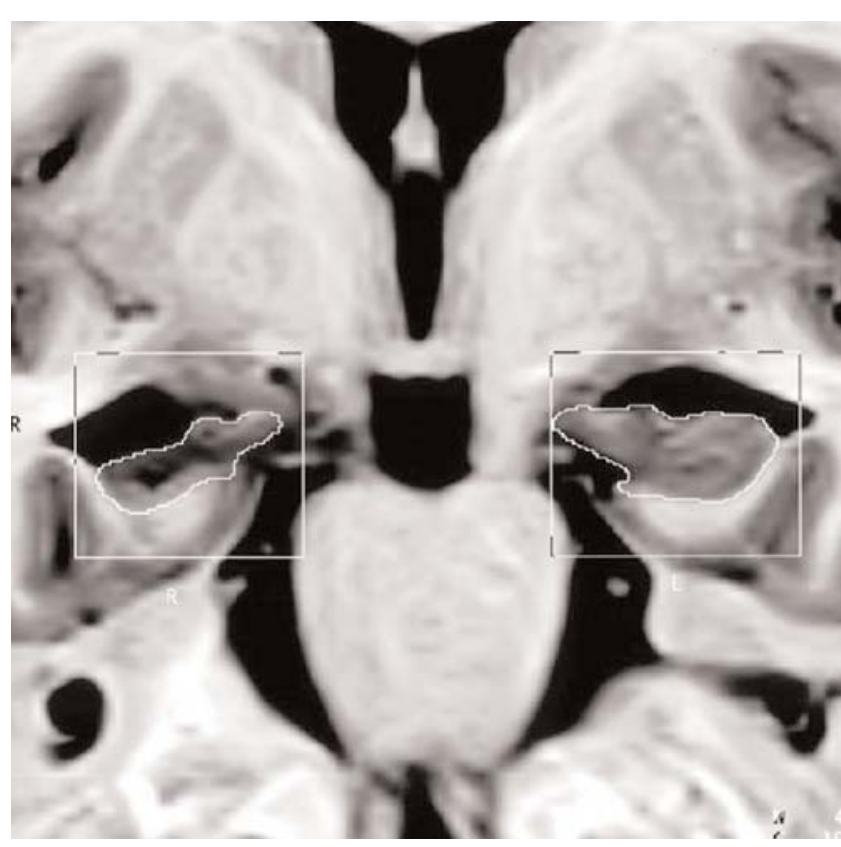

Figure 2. Hippocampal area measurement. From "Morphometry of some elements of limbic system in normal population: a quantitative MRI study" by Yücel K, Hakyemez B, Parlak M, Oygucu IH. Neuroanatomy 2002;1:15$21 .{ }^{[33]} \odot$ neuroanatomy.org. Reprinted with permission.

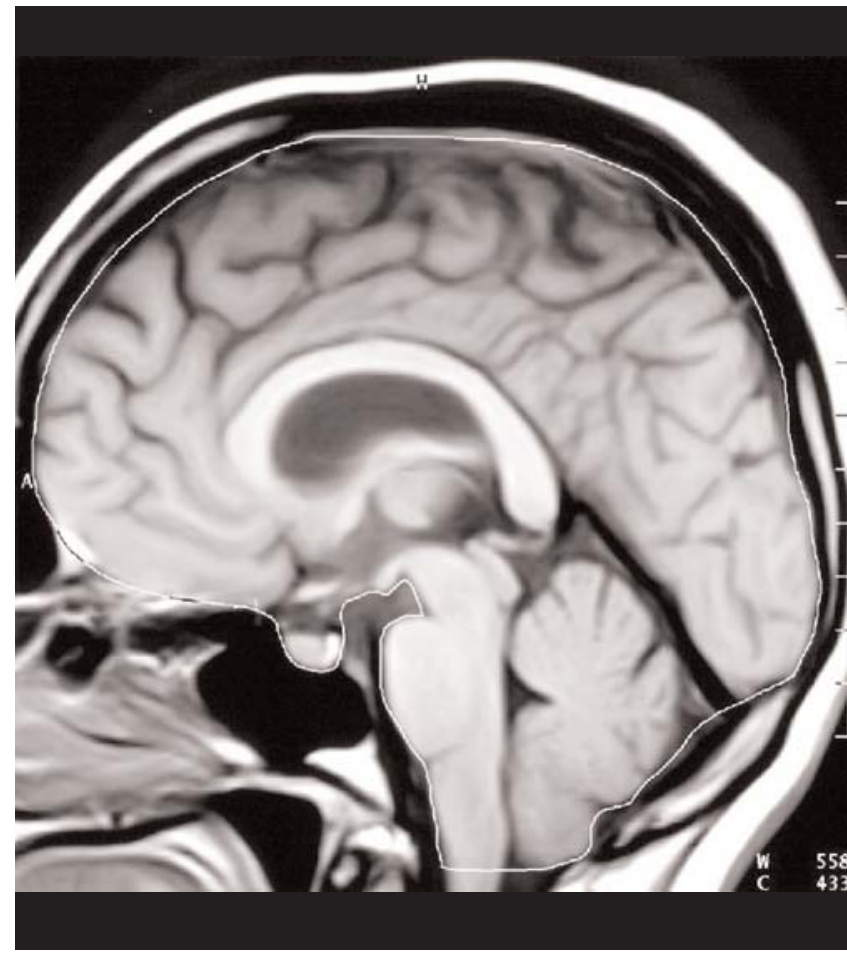

Figure 1. Intracranial measurement of mid-sagittal area of a subject. From "Morphometry of some elements of limbic system in normal population: a quantitative MRI study" by Yücel K, Hakyemez B, Parlak M, Oygucu IH. Neuroanatomy 2002;1:15-21. ${ }^{[3]]}$ Oneuroanatomy.org. Reprinted with permission.

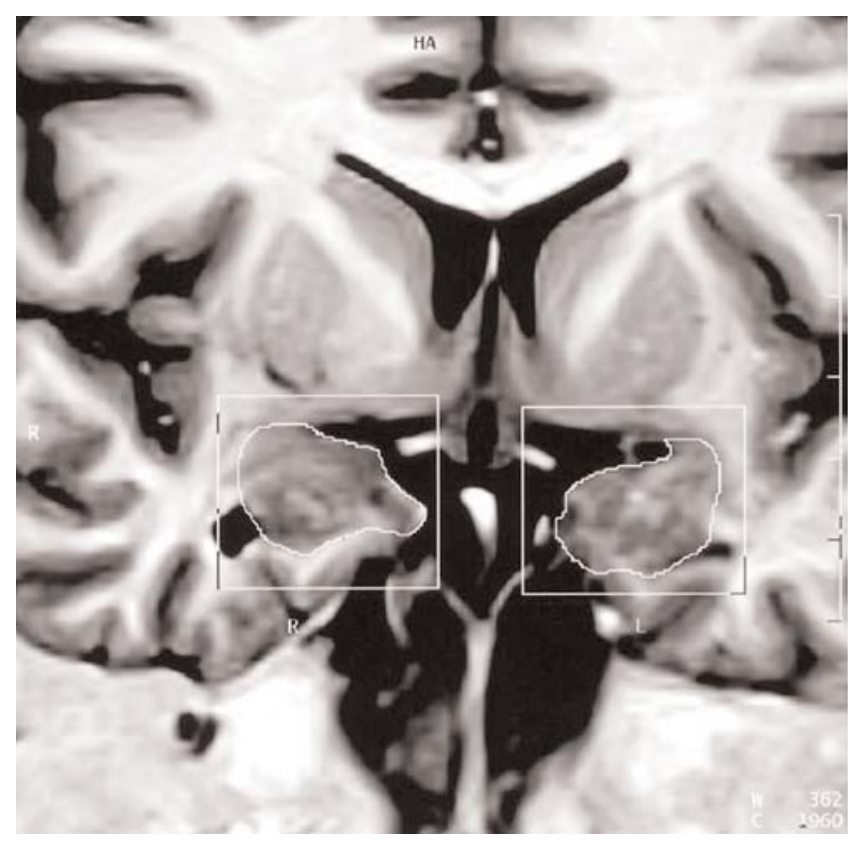

Figure 3. Amygdaloid body area measurement. From "Morphometry of some elements of limbic system in normal population: a quantitative MRI study" by Yücel K, Hakyemez B, Parlak M, Oygucu IH. Neuroanatomy 2002;1:15-21. ${ }^{[33]} \odot$ neuroanatomy.org. Reprinted with permission. 


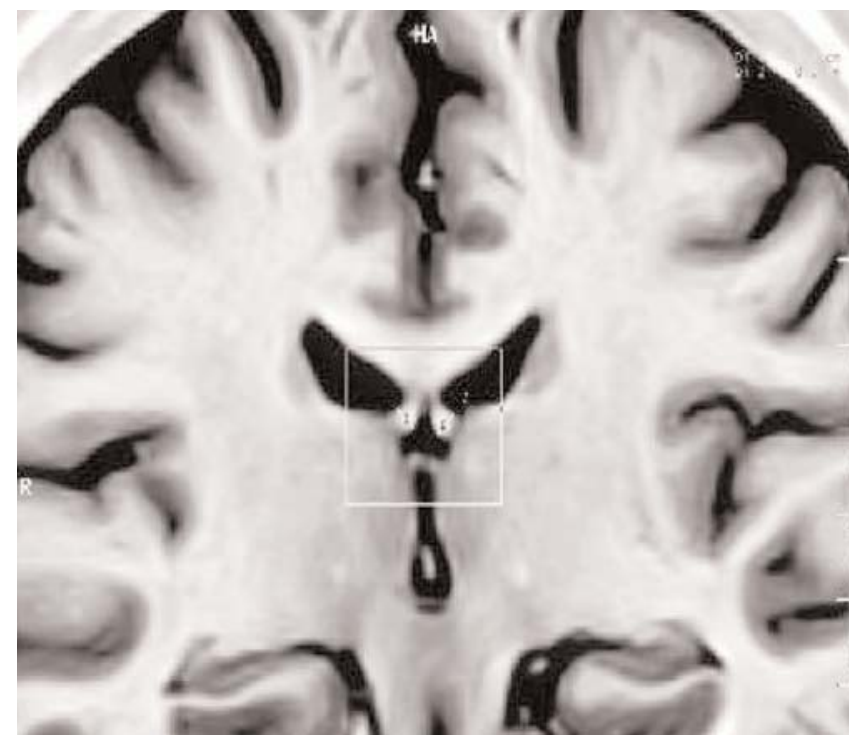

Figure 4. Fornix width measurement on a coronal section. From "Morphometry of some elements of limbic system in normal population: a quantitative MRI study" by Yücel K, Hakyemez B, Parlak M, Oygucu IH. Neuroanatomy 2002;1:15-21..$^{[33]}$ @ neuroanatomy.org. Reprinted with permission.

Fornix width was measured at the coronal section where crus of fornix from the right and left side gather to form the corpus fornicis (Figure 4) ${ }^{[10]}$ The width of mamilary body was measured at the section where hippocampal digitations were seen at the hippocampal head (Figure 5). ${ }^{[11]}$ In the epilepsy neuroimaging literature particularly, in order to define atrophy in the hippocampus and amygdaloid body, normative data from a properly matched control group has been used. ${ }^{[37,38]}$ Accordingly, the values 2 standart deviations below the mean volumes of the control group for hippocampus and amygdaloid body and the width of fornix and mammillary bodies were considered as "atrophic". In order to compare the sizes of the anatomical structures measured between TLE-CFC $[+]$ patients and TLE-CFC[-] patients we took the amount of atrophy into consideration. We used two different formulas to detect the amount of atrophy quantitatively in hippocampus/amygdaloid body and fornix/mammillary bodies. The first formula was for assessing hippocampal and amygdaloid atrophy calculating the absolute difference between right and left hippocampal and amygdaloid volume (R-L) in the TLE group. The second formula was the "\% difference rate" for measuring the width of fornix and mamilary body as demonstrated below:

$$
\% \text { difference rate }=\frac{(\text { larger } \text { side }- \text { smaller side })}{\text { larger } \text { side }} \times 100
$$

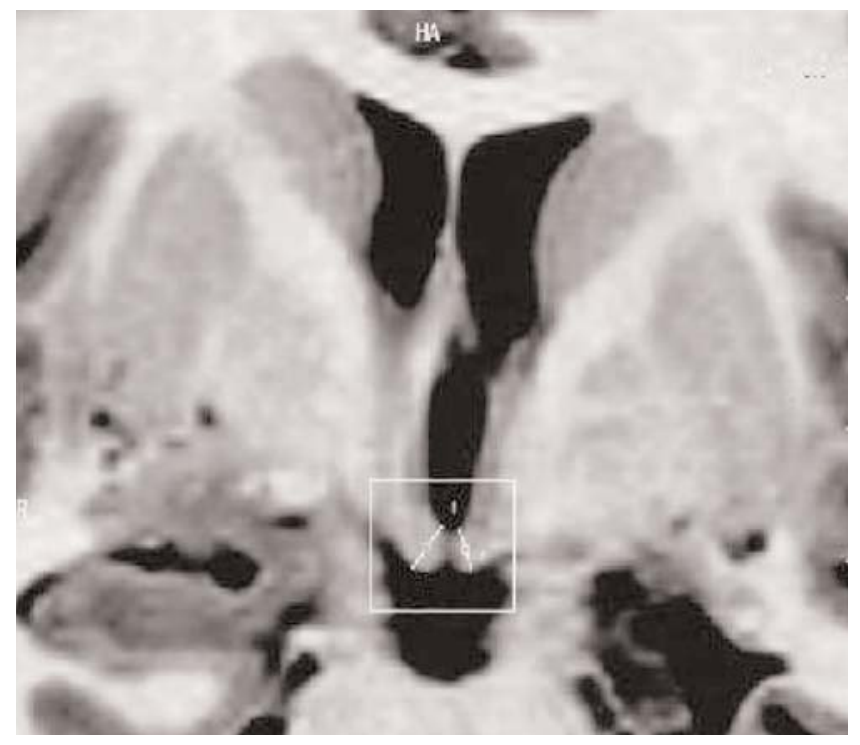

Figure 5. Mamillary body width measurement on a coronal section. From "Morphometry of some elements of limbic system in normal population: a quantitative MRI study" by Yücel K, Hakyemez B, Parlak M, Oygucu $\mathbb{H}$. Neuroanatomy 2002;1:15-21..$^{[33]}$ @ neuroanatomy.org. Reprinted with permission.

$\%$ difference rate was also helpful detecting the number of patients with and without atrophy of these two structures when compared with the 2 standard deviations above the mean of the control group as an overlapping exists in fornix and mamillary body sizes between the normal cases and pathological cases. ${ }^{[1]]}$ Regarding fornix or mamillary body \% difference rates of standart deviations above the mean of control group for these was considered as "atrophic."

The results of our study were assessed using Statistical Package for Social Sciences (SPSS Version 7, Armonk; NY, USA). In comparing the results of patient and control group t-test and Mann-Whitney U test were used. For the correlations Pearlson's correlation rate was used. For all the comparisons, p-values less than 0.05 were considered as significant.

\section{Results}

We found no difference between TLE and control group in terms of age ( $>0.05)$. The years of education were different between the two groups $(p>0.05)$. The demographic data of the TLE and control group are shown in Table 1 . The mean of seizure frequency in the patient group was 5.66 seizures/per month (0.08-25). After performing partial correlations it was found that this variable had an effect on normalized amygdaloid body volume and fornix \% difference rate. After control- 
Table 1

Demographic data in TLE and control group including age, education, age at onset of epilepsy, epilepsy duration.

\begin{tabular}{lcccc} 
Group & $\begin{array}{c}\text { Age } \\
\text { Mean } \pm \text { SD (min-max) }\end{array}$ & $\begin{array}{c}\text { Education (years) } \\
\text { Mean } \pm \text { SD (min-max) }\end{array}$ & $\begin{array}{c}\text { Age at onset of epilepsy } \\
\text { Mean } \pm \text { SD (min-max) }\end{array}$ & $\begin{array}{c}\text { Epilepsy duration (years) } \\
\text { Mean } \pm S D(m i n-m a x)\end{array}$ \\
\hline TLE & $30.69 \pm 13.34(10-67)$ & $7.76 \pm 3.97(0-15)$ & $14.59(9$ month-42 years) & $16.24(2-54)$ \\
\hline Control & $31.09 \pm 12.06(13-62)$ & $11.97 \pm 4.21(0-17)$ & - & - \\
\hline Statistical significance & 0.775 & $<0.05$ & - & - \\
\hline
\end{tabular}

Max: maximum value; min: minimum value; SD: standart deviation.

Table 2

The dispertion of cases with history of CFC in the TLE and control group.

\begin{tabular}{|c|c|c|}
\hline Group & Number of cases with a history of CFC & Number of cases without a history of CFC \\
\hline TLE $(n=42)$ & 19 (8 females, 11 males) & 23 (11 females, 12 males) \\
\hline Control $(n=42)$ & 2 ( 1 male, 1 female) & 40 (18 females, 22 males) \\
\hline Statistical significance & $p<0.01$ & $p<0.01$ \\
\hline
\end{tabular}

ling for numbers of years of education variable, the results of the study with statistical significance remained the same.

We found no difference between TLE-CFC[+] patients and TLE-CFC[-] patients in terms of age of epilepsy onset, epilepsy duration and seizure frequency ( $>0.05)$. There was no difference between the TLE$\mathrm{CFC}[+]$ patients and TLE-CFC[-] patients according to age and gender $(p>0.05)$. In TLE group the number of cases with a history of CFC was more than the cases with such a history in the control group $(\mathrm{p}<0.01)$. The distribution of number of cases with and without history of CFC in both groups are demonstrated in Table 2.

There was no difference between TLE-CFC[+] patients and TLE-CFC[-] patients in terms of all the quantitative measurements results $(p>0.05)$ except the atrophy rate of hippocampus and fornix \% difference rate $(\mathrm{p}<0.01, \mathrm{p}<0.05$ respectively) (Table 3$)$.

\section{Table 3}

Comparison of quantitative measurements of hippocampus, amygdala, fornix and mamillary body between TLE patients with and without a history of CFC.

\begin{tabular}{|c|c|c|c|}
\hline & $\begin{array}{l}\text { TLE patients with a history of CFC } \\
(n=19) \text { Mean } \pm \text { SD (min-max) }\end{array}$ & $\begin{array}{l}\text { TLE patients without a history of CFC } \\
\quad(n=23) \text { Mean } \pm \text { SD (min-max) }\end{array}$ & $\begin{array}{r}\text { Statistical } \\
\text { significance }\end{array}$ \\
\hline Right hippocampus volume & $2968.78 \pm 769.29(1886.56-4099.55)$ & $3189.77 \pm 843.49(1110.56-4456.81)$ & $p>0.05$ \\
\hline Left hippocampus volume & $2849.38 \pm 583.56(1889.51-4550.41)$ & $3115.05 \pm 583.56(1889.51-4550.41)$ & $p>0.05$ \\
\hline Amount of atrophy in the hippocampus $(22 \mathrm{~m}, 16 \mathrm{f})$ & $1471.06 \pm 575.17(47.5-2334.35)$ & $819.90 \pm 611.08(9.19-1919.93)$ & $p<0.01 *$ \\
\hline Right amygdala volume & $1987.73 \pm 361.96(1224.83-2618.22)$ & $2149.12 \pm 365.2(1406.29-2699.11)$ & $p>0.05$ \\
\hline Left amygdala volume & $1918.57 \pm 388.09(977.27-2552.24)$ & $2085.44 \pm 341.09(1380.9-2561.55)$ & $p>0.05$ \\
\hline Amount of atrophy in the amygdala $(22 \mathrm{~m}, 15 \mathrm{f})$ & $358.59 \pm 331.82(6.07-965.31)$ & $292.33 \pm 331.82(6.07-965.31)$ & $p>0.05$ \\
\hline Right fornix width & $2.3 \pm 0.05(1-3.4)$ & $2.48 \pm 0.06(1.4-3.9)$ & $p>0.05$ \\
\hline Left fornix width & $2.46 \pm 0.05(1.3-4.8)$ & $2.59 \pm 0.05(1.4-43.9)$ & $p>0.05$ \\
\hline$\%$ fornix difference rate & $23.43 \pm 17.99(0-56.52)$ & $13.74 \pm 16.54(0-47.37)$ & $p<0.05^{*}$ \\
\hline Right mamillary body width & $4.26 \pm 0.06(3.3-5.3)$ & $4.09 \pm 0.06(2.3-5.6)$ & $p>0.05$ \\
\hline Left mamillary body width & $4.24 \pm 0.06(3-5.4)$ & $4.17 \pm 0.06(2.7-5.5)$ & $p>0.05$ \\
\hline$\%$ mammillary body difference rate & $7.78 \pm 8.66(0-25)$ & $7.17 \pm 8.14(0-36.36)$ & $p>0.05$ \\
\hline
\end{tabular}

F: females; M: males; hippocampus and amygdala quantitative values are expressed as $\mathrm{mm}^{3}$; fornix and mamillary body widths are expressed as $\mathrm{mm}$; *statistically significant. 
Ten of the patients with hippocampal atrophy did not have a history of CFC while 14 had. Twelve of 14 patients with normal hippocampal size did not have a history of CFC and only 2 patients with normal hippocampus size had. The difference between the two groups was statistically significant $(\mathrm{p}<0.01)$. Fourteen of 20 patients without forniceal atrophy, did not have a history of CFC and 6 had. Nine of 22 patients with forniceal atrophy did not have a history of CFC while $13 \mathrm{had}$. The dispersion of patients with and without a history of CFC between the two groups had tendency to be statistically significant $(\mathrm{p}=0.059)$. Fourteen of 24 patients without atrophy of mammillary bodies, and amygdaloid body atrophy did not have a history of CFC and 10 had. Nine of 18 patients with atrophy of mammillary bodies and amygdaloid body did not have a history of CFC while 9 had. The dispersion of patients TLE-CFC $[+]$ patients and TLE-CFC[-] patients between the two groups was not significant $(p>0.05)$.

\section{Discussion}

We found no differences in bilateral hippocampus and amygdaloid body volumes and fornix and mamillary body widths between TLE-CFC $[+]$ patients and TLE-CFC[-] patients. On the other hand, the amount of atrophy in the hippocampus and fornix were more in TLE-CFC $[+]$ patients. We found that TLE-CFC[+] patients had more reduction in hippocampal volume with a mean of $8.36 \%$ than TLE-CFC[-] patients.

Some studies reported atrophy in the hippocampus of TLE-CFC[+] patients compared to TLE-CFC[-] patients, ${ }^{[13,18,26,28]}$ although some reported no relation between hippocampal atrophy and history of CFC. ${ }^{[2,39]}$ Several different mechanisms have been proposed to explain the role of CFCs in the atrophy of medial temporal structures in MTS. One of the theories suggest a further susceptibility of the hippocampus to seizures in the adulthood following cellular and molecular changes occurred following CFC experienced in childhood. ${ }^{[4]}$ An other mechanism is that an initially pre-existing insult can make hippocampal damage to cause CFC initially and then to TLE. ${ }^{[25]}$ Common genetic mechanisms for the development of CFC and TLE have been suggested as a third theory. ${ }^{[4]]}$ However, not each case with hippocampal atrophy has a history of CFC. In fact, there is only a certain small group of TLE-CFC[+] patients. Factors such as head trauma, afebrile status epilepticus and meningitis can also cause MTS ${ }^{[42]}$ As a result we can say that CFC is not the solely etiologic factor of TLE, but only can be one the factors.

We found that history of CFC was not related to any volumetric changes in the amygdaloid body in TLE patients consistent with the findings of the previous stud- ies. ${ }^{[27,34]}$ Actually, amygdaloid body has been related to the psychogenic auras seen in TLE patients, rather than an insult related to the CFC experienced in the childhood ${ }^{[27,43]}$ and hippocampus has a more dominant role than amygdaloid body has for the origin of epileptic seizures. ${ }^{[4]}$

In spite of their inconsistencies, there are many studies where correlations were reported between hippocampus and amygdaloid body volumes and epilepsy duration, age of onset and seizure frequency. ${ }^{[13,18,45]}$ Parallel to the findings of Bower et al. ${ }^{[39]}$ and Fuerst et al. ${ }^{[46]}$ we found no difference between TLE-CFC[+] patients and TLE-CFC[-] patients regarding these three variables. Therefore we do not think that they can affect our findings.

Finally, as far as we know more forniceal atrophy in TLE-CFC $[+]$ patients is a new finding. Thinner fornix has been reported previously in TLE patients compared to the controls. ${ }^{[47]}$ It was proposed that forniceal atrophy was associated with relatively larger hippocampal volume loss in TLE. ${ }^{[4]}$ There is only one study with adults with a history of childhood febrile seziures and the authors did not find any difference in forniceal integrity between this sample and controls. ${ }^{[2]}$ Fornix is one of the pathways for seizure spreading along with other pathways including stria terminalis, amygdalofugal fibers, and uncinate fasciculus. ${ }^{[4]}$ An increase in white matter integrity was observed in a group of subjects whose diffussion tensor imaging (DTI) scans were performed eight years after the prolonged febrile seizures compared to controls. ${ }^{[4]} \mathrm{We}$ can speculate that fornix atrophy associated with the history of CFC can be secondary to the hippocampal atrophy seen in TLE patients. Considering the proposed mechanisms for the relationship between hippocampus atrophy and $\mathrm{CFC}$, what has been said about the hippocampus may also apply to the fornix; i.e. fornix atrophy may have occurred due to a trauma before CFC or the direct effect of CFC. In this neuroimaging study of ours, however, we can not explain the mechanism of the relation between forniceal atrophy and history of CFC in TLE patients. TLE patients with relatively more hippocampal atrophy and history of CFC can be a separate clinical group, and more forniceal atrophy might be a feature of this particular group of TLE patients.

The point of view from a perspective on genetics is very important when planning future MRI morphometric measurements to uncover the relation between history of CFC and TLE. For example, why not every child with a history of CFC develops TLE and related hippocamapal damage may be answered partly by planning collaborative prospective studies of genetics and MRI morphometery.

Our study has several limitations. First, it is a cross-sectional study with relatively a small sample size. We do not 
have any treatment history, as the antiepileptics also can be a confounding factor. Rather than measuring the width of the fornix, DTI as a relatively new and more advanced technique might have been used to see whether there is any deficit in the white matter integrity in this pathway in this subgroup of TLE patients. ${ }^{[50]}$

In our study, we replicated the consistent finding of more hippocampal atrophy in TLE-CFC $[+]$ patients with an additional finding of more forniceal atrophy in that group of patients compared to those patients TLE-CFC[-] patients. The CFCs should be taken care of carefully in the childhood, as they are associated with more atrophy in the particular brain structures in patients with TLE.

\section{Conflict of Interest}

The authors declare that there is no conflict of interest.

\section{Author Contributions}

$\mathrm{KY}$ : project development, manuscript writing/editing; $\mathrm{BH}$ : data collection and data analysis; IB: supervision of the study and collecting patients.

\section{Ethics Approval}

The study was approved by the Local Ethics Committee of the Medical School of Uludag University (date of approval: 09.05.2000, approval number: 2000-51).

\section{Funding}

The study was not conducted by any available funding resources.

\section{References}

1. Cho YW, Kim KT. The latest classification of epilepsy and clinical significance of electroencephalography. Journal of Neurointensive Care 2019;2:1-3.

2. Fiest KM, Sauro KM, Wiebe S, Patten SB, Kwon CS, Dykeman J, Pringsheim T, Lorenzetti DL, Jetté N. Prevalence and incidence of epilepsy: a systematic review and meta-analysis of international studies. Neurology 2017;88:296-303.

3. Blair RD. Temporal lobe epilepsy semiology. Epilepsy Res Treat 2012;2012:751510.

4. Cendes F. Mesial temporal lobe epilepsy syndrome: an updated overview. Journal of Epilepsy and Clinical Neurophysiology 2005;11: $141-4$.

5. Farias-Serratos F, Kensuke K, Nobuhito S. Temporal lobe epilepsy. Archivos de Neurociencias (Mex) 2014;19:88-94.

6. Granados Sánchez AM, Orejuela Zapata JF. Diagnosis of mesial temporal sclerosis: sensitivity, specificity and predictive values of the quantitative analysis of magnetic resonance imaging. Neuroradiol J 2018;31:50-9.

7. Beheshti I, Sone D, Farokhian F, Maikusa N, Matsuda H. Gray matter and white matter abnormalities in temporal lobe epilepsy patients with and without hippocampal sclerosis. Front Neurol 2018;13;9; 107.
8. Sone D, Ota M, Maikusa N, Kimura Y, Sumida K, Yokoyama K, Imabayashi E, Watanabe M, Watanabe Y, Okazaki M, Sato N, Matsuda H. White matter abnormalities in patients with temporal lobe epilepsy and amygdaloid body enlargement: comparison with hippocampal sclerosis and healthy subjects. Epilepsy Res 2016;127: 221-8.

9. Cascino GD. Temporal lobe epilepsy: more than hippocampal pathology. Epilepsy Curr 2005;5:187-9.

10. Baldwin GN, Tsuruda JS, Maravilla KR, Hamill GS, Hayes CE. The fornix in patients with seizures caused by unilateral hippocampal sclerosis: detection of unilateral volume loss on MR images. AJR Am J Roentgenol 1994;162:1185-9.

11. Ng SE, Lau TN, Hui FK, Chua GE, Lee WL, Chee MW, Chee TS, Boey HK. MRI of the fornix and mamillary body in temporal lobe epilepsy. Neuroradiology 1997;39:551-5.

12. O’Brien CE, Cook MJ, Boweden S, Vogrin SJ. Modelling human medial temporal lobe structures and mamillary bodies using volumetric MRI. Proceedings of Annual Meeting of the American Epilepsy Society, Orlando, Florida, United States of America. Epilepsia 1999; 40:188.

13. Salmenpera T, Kalviainen R, Partanen K, Pitkanen A. Hippocampal and amygdaloid damage in partial epilepsy: a cross-sectional MRI study of 241 patients. Epilepsy Res 2001;46:69-82.

14. Rocca WA, Sharbrough FW, Hauser WA, Annegers JF, Schoenberg BS. Risk factors for complex partial seizures: a population-based casecontrol study. Annals of Neurology 1987;21:22-31.

15. Baram TZ, Jackson GD, Soltesz I, Sperber EE. Do febrile seizures cause temporal lobe epilepsy? an update. Proceedings of Annual Meeting of the American Epilepsy Society, Orlando, Florida, United States of America, Epilepsia 1999;40:S3.

16. Berg AT, Shinnar S. Complex febrile seizures. Epilepsia 1996;37:12633.

17. Tasch E, Cendes F, Li LM, Dubeau F, Andermann F, Arnold DL. Neuroimaging evidence of progressive neuronal loss and dysfunction in temporal lobe epilepsy. Ann Neurol 1999;45:568-76.

18. Spanaki MV, Kopylev L, Liow K, DeCarli C, Fazilat S, Gaillard WD, Theodore WH. Relationship of seizure frequency to hippocampus volume and metabolism in temporal lobe epilepsy. Epilepsia 2000;41: 1227-9.

19. Cendes F, Andermann F, Dubeau F, Gloor P, Evans A, JonesGotman M, Olivier A, Andermann E, Robitaille Y, Lopes-Cendes I, Peters T, Melanson D. Early childhood prolonged febrile convulsions, atrophy and sclerosis of mesial structures, and temporal lobe epilepsy: an MRI volumetric study. Neurology 1993;43:10837.

20. Maher J, McLachlan RS. Febrile convulsions. Is seizure duration the most important predictor of temporal lobe epilepsy? Brain 1995;118: 1521-8.

21. Gulec G, Noyan B. Do recurrent febrile convulsions decrease the threshold for pilocarpine-induced seizures? Effects of nitric oxide. Brain Res Dev Brain Res 2001;126:223-8.

22. Sagar HJ, Oxbury JM. Hippocampal neuron loss in temporal lobe epilepsy: correlation with early childhood convulsions. Ann Neurol 1987;22:334-40.

23. Meldrum BS. Anatomy, physiology, and pathology of epilepsy. Lancet 1990;336:231-4.

24. Al Sufiani F, Ang LC. Neuropathology of temporal lobe epilepsy. Epilepsy Res Treat 2012;2012:624519. 
25. Patterson KP, Baram TZ, Shinnar S. Origins of temporal lobe epilepsy: febrile seizures and febrile status epilepticus. Neurotherapeutics 2014;11:242-50

26. Cendes F, Andermann F, Gloor P, Lopes-Cendes I, Andermann E, Melanson D, Jones-Gotman M, Robitaille Y, Evans A, Peters T. Atrophy of mesial structures in patients with temporal lobe epilepsy: cause or consequence of repeated seizures? Ann Neurol 1993;34:795801.

27. Santana MT, Jackowski AP, da Silva HH, Caboclo LO, Centeno RS, Bressan RA, Carrete H Jr, Yacubian EM. Auras and clinical features in temporal lobe epilepsy: a new approach on the basis of voxel-based morphometry. Epilepsy Res 2010;89:327-38.

28. Finegersh A, Avedissian C, Shamim S, Dustin I, Thompson PM, Theodore WH. Bilateral hippocampal atrophy in temporal lobe epilepsy: effect of depressive symptoms and febrile seizures. Epilepsia 2011;52:689-97.

29. Gong G, Alexander RP, Shi F, Beaulieu C, Gross DW. Isolated febrile seizures are not associated with structural abnormalities of the limbic system. Epilepsy Res 2012;102:216-20.

30. Adam C, Baulac M, Saint-Hilaire JM, Landau J, Granat O, Laplane D. Value of magnetic resonance imaging-based measurements of hippocampal formations in patients with partial epilepsy. Arch Neurol 1994;51:130-8.

31. Güven A, Deda G, Şalvarlı Ş, Uysal S, Erden I, Karagöl U. Measurement of hippocampal volume in children with early febrile seizures. Proceedings of 23rd International Epilepsy Congress, Prag, Czech Republic. Epilepsia 1999;40:S45.

32. Cendes F, Andermann F, Gloor P, Evans A, Jones-Gotman M, Watson C, Melanson D, Olivier A, Peters T, Lopes-Cendes I, Leroux G. MRI volumetric measurement of amygdaloid body and hippocampus in temporal lobe epilepsy. Neurology 1993;43:719-25.

33. Yücel K, Hakyemez B, Parlak M, Oygucu IH. Morphometry of some elements of limbic system in normal population: a quantitative MRI study. Neuroanatomy 2002;1:15-21.

34. Free SL, Bergin PS, Fish DR, Cook MJ, Shorvon SD, Stevens JM Methods for normalization of hippocampal volumes measured with MR. JNR Am J Neuroradiol 1995;16:637-43.

35. Cook M, Stevens JM. Imaging in epilepsy. In: Hopkins A, Shorvon S, Cascino G, editors. Epilepsy, 2nd ed. London: Chapman and Hall Medial; 1995. p. 143-54.

36. Cook MJ, Fish DR, Shorvon SD, Straughan K, Stevens JM. Hippocampal volumetric and morphometric studies in frontal and temporal lobe epilepsy. Brain 1992;115:1001-15.

37. Jack CR Jr, Sharbrough FW, Twomey CK, Cascino GD, Hirschorn KA, Marsh WR, Zinsmeister AR, Scheithauer B. Temporal lobe seizures: lateralization with MR volume measurements of the hippocampal formation. Radiology 1990;175:423-9.

38. Farid N, Girard HM, Kemmotsu N, Smith ME, Magda SW, Lim WY, Lee RR, McDonald CR. Temporal lobe epilepsy: quantitative MR volumetry in detection of hippocampal atrophy. Radiology 2012; 264:542-50.

39. Bower SP, Kilpatrick CJ, Vogrin SJ, Morris K, Cook MJ. Degree of hippocampal atrophy is not related to a history of febrile seizures in patients with proved hippocampal sclerosis. J Neurol Neurosurg Psychiatry 2000;69:733-88.

40. Notenboom RGE, Ramakers GMJ, Kamal A, Spruijt BM, de Graan PNE. Long-lasting modulation of synaptic plasticity in rat hippocampus after early-life complex febrile seizures. Eur J Neurosci 2010;32: 749-58.

41. Li Y, Wang C, Wang P, Li X, Zhou L. Effects of febrile seizures in mesial temporal lobe epilepsy with hippocampal sclerosis on gene expression using bioinformatical analysis. Acta Epileptologica 2020;2: 20.

42. Ramantani G, Holthausen H. Epilepsy after cerebral infection: review of the literature and the potential for surgery. Epileptic Disord 2017;19:117-36.

43. Baulac M. MTLE with hippocampal sclerosis in adult as a syndrome. Rev Neurol (Paris) 2015;171:259-66.

44. Mayanagi Y, Watanabe E, Kaneko Y. Mesial temporal lobe epilepsy: clinical features and seizure mechanism. Epilepsia 1996;37:S57-S60.

45. Kim JS, Koo DL, Joo EY, Kim ST, Seo DW, Hong SB. Asymmetric gray matter volume changes associated with epilepsy duration and seizure frequency in temporal-lobe-epilepsy patients with favorable surgical outcome. J Clin Neurol 2016;12:323-31.

46. Fuerst D, Shah J, Kupsky WJ, Johnson R, Shah A, Hayman-Abello B, Ergh T, Poore Q, Canady A, Watson C. Volumetric MRI, pathological, and neuropsychological progression in hippocampal sclerosis. Neurology 2001;57:184-8.

47. Mamourian AC, Cho CH, Saykin AJ, Poppito NL. Association between size of the lateral ventricle and asymmetry of the fornix in patients with temporal lobe epilepsy. AJNR Am J Neuroradiol 1998;19:9-13.

48. Kim JH, Tien RD, Felsberg GJ, Osumi AK, Lee N. Clinical significance of asymmetry of the fornix and mamillary body on MR in hippocampal sclerosis. AJNR Am J Neuroradiol 1995;16:509-15.

49. Pujar SS, Seunarine KK, Martinos MM, Neville BGR, Scott RC, Chin RFM, Clark CA. Long-term white matter tract reorganization following prolonged febrile seizures. Epilepsia 2017;58:772-80.

50. Fitsiori A, Hiremath SB, Boto J, Garibotto V, Vargas MI. Morphological and advanced imaging of epilepsy: beyond the basics. Children (Basel) 2019;6:43.
ORCID ID:

K. Yücel 0000-0001-9606-8808; B. Hakyemez 0000-0002-3425-0740

I. Bora 0000-0002-9435-6037
Correspondence to: Kaan Yücel MD, PhD Department of Anatomy, School of Medicine, Izmir Democracy University, Konak, 35290, Izmir, Turkey. Phone: +90 5322438422 e-mail: kaanyucel2014@gmail.com

Conflict of interest statement: No conflicts declared.

This is an open access article distributed under the terms of the Creative Commons Attribution-NonCommercial-NoDerivs 4.0 Unported (CC BY-NCND4.0) Licence (http://creativecommons.org/licenses/by-nc-nd/4.0/) which permits unrestricted noncommercial use, distribution, and reproduction in any medium, provided the original work is properly cited. How to cite this article: Yücel K, Hakyemez B, Bora İ. Forniceal and hippocampal atrophy in temporal lobe epilepsy patients with a history of complex febrile convulsion. Anatomy 2021;15(2):137-144. 